\title{
Cooperación y academia: una relación pendiente en Colombia
}

Luz Rocío Corredor González*

\author{
Reseña de libro \\ Marín Aranguren, E. M. y Ruiz Camacho, P. X. (Editores). (2017). Cooperación y academia: \\ una relación pendiente en Colombia. Bogotá: Universidad Externado de Colombia
}

Hablar de cooperación internacional en Colombia y en el mundo siempre será apasionante y un reto. De un lado, porque el tema conlleva elementos desde lo técnico y lo político. Del otro, por el espíritu social y el impacto económico que conlleva cada decisión. Piénsese no más en la asignación de recursos, en el diseño e implementación de programas y proyectos, para no entrar en los debates sobre la racionalización y la optimización de los recursos de cooperación.

Adicionalmente, es un reto por constituirse en un tema que no es tan abordado en su esencia ni en su dimensión real como debiera, por tanto, es un tema inacabado, limitadamente explorado, pero es un amplio objeto de estudio. Es por ello que el libro que aquí se reseña Cooperación y academia. Una relación pendiente en Colombia agrega un elemento importante para el análisis, por lo menos en Colombia. En concreto pone en el centro a la academia que debe ser protagonista del manejo del tema desde la investigación para comprender el contexto y para convertirse en ese centro de pensamiento que ha de plantear alternativas para el proceso de toma de decisiones de política. De hecho, la misma academia es la llamada a incorporar el tema en los currículos de los programas de pregrado de las ciencias sociales y las ciencias económicas, de modo que no solo se conozca la arquitectura de la cooperación internacional, sus implicaciones, sino que se motive a los educandos a la investigación para comprender dificultades, sistematizar lecciones

* Doctoranda en estudios políticos, Facultad de Finanzas, Gobierno y Relaciones Internacionales, Universidad Externado de Colombia, profesora e investigadora. Directora del Grupo de Investigación Desarrollo y Equidad, Facultad de Economía, Universidad América. (Colombia) [luz.corredor@profesores.uamerica.edu.co].

Para citar esta reseña:

Corredor González, L. R. (2018). Cooperación y academia: una relación pendiente en Colombia [Reseña: Marín Aranguren, E. M. y Ruiz Camacho, P. X. (Editores). (2017). Cooperación y academia: una relación pendiente en Colombia. Bogotá: Universidad Externado de Colombia]. OASIS, 28, pp. 205-208.

DOI: https://doi.org/10.18601/16577558.n28.13 
aprendidas y presentar iniciativas y proyectos coherentes y de alto impacto, más ahora que el país debe tomar su rol de donante y socio a la vez. Ahora cuando las instituciones de los gobiernos subnacionales y nacionales también se están insertando en las nuevas dinámicas y realidades del posconflicto.

Marín Aranguren y Ruiz Camacho presentan un libro con una estructura pedagógica y metodológica en tres partes, la cual permite ubicar en contexto a la cooperación internacional y los distintos roles que puede llegar a desempeñar en la vida de un país de renta media alta como el colombiano, que es un caso atípico en términos de cooperación, que siendo país de renta media sigue siendo sujeto prioritario de la cooperación por lo que implica la situación coyuntural en la que se encuentra, en términos de pobreza, desplazamiento forzado y desigualdad.

En realidad, esta condición contextual se ha investigado como estudio de caso en los Programas de Desarrollo y Paz del Magdalena Medio o Laboratorios de Paz, pero no para caracterizar la cooperación en temas de conflicto, ni para proponer mecanismos de optimización de acceso a los recursos. Tampoco se puede anotar que haya escritos en los que se haga mayor referencia a la identificación de necesidades o a la priorización de metodologías que posibiliten generar un mayor impacto. Es claro que, si bien existen muchas modalidades de cooperación que incluyen la cooperación técnica, por lo general, asociada a la cooperación oficial al desarrollo AOD, la cooperación descentralizada, que involucra actores en los territorios, la cooperación Sur-Sur y la cooperación al desarrollo, es la cooperación Sur-Sur la que se ha convertido en protagonista no solo en Colombia sino en el mundo. Estas son abordadas por los coautores del libro editado por la Universidad Externado de Colombia. En la primera parte, Sistema Internacional de Cooperación y su mutación, se encuentran tres capítulos que caracterizan, por un lado, la cooperación internacional como herramienta para el desarrollo económico a largo plazo, evidenciando que si se traza una hoja de ruta adecuada, trabajando desde los territorios e involucrando a las comunidades como actores constructores de su desarrollo, responsables de identificar una vocación productiva que puede potencializarse con el paso del tiempo en unas metas, los impactos podrán traducirse en oportunidades de crecimiento sostenido y sostenible para dichos territorios.

En un segundo momento, Cooperación internacional y relaciones euro latinoamericanas, evalúa esa alianza protagónica de la Unión Europea como mayor cooperante de América Latina y su responsabilidad en la herencia de una dependencia de receptor pasivo y no de actor participante de respuestas generadoras de construcción de paz y, por tanto, de desarrollo sostenible desde sus propios requerimientos y expectativas.

Y para cerrar la primera parte, nos encontramos con la academia en moratoria: vacíos en la investigación sobre cooperación internacional en Colombia y sus implicaciones, que no es otra cosa que un llamado a la necesidad de convocar a la construcción de redes de conocimiento y buenas prácticas alrededor de la cooperación internacional como un acto de responsabilidad social y de compromiso ciudadano frente a la coyuntura actual de 
posconflicto, pero también a un desaprovechamiento total de optimización de recursos, no solo financieros sino técnicos, por desconocimiento y que quizás hubiesen facilitado la construcción de un país distinto desde las regiones, teniendo claro que el conflicto fue generado por territorios y que desde ellos, con el concurso de la academia, pudieran haberse generado mejores y más reales escenarios para el desarrollo y consolidación prospectiva de estos escenarios.

Esta primera parte, entonces, contextualiza el mundo de la cooperación como una de las interacciones básicas del sistema internacional y sus actores y los cambios de unas dinámicas con variables incontrolables como la asignación de recursos desde las Agencias de Cooperación Internacional y unas externalidades controlables como el manejo, seguimiento e impactos de la misma de acuerdo con la racionalidad económica y con la vulnerabilidad social, que quizás hubieran impedido escenarios como la propia profundización del conflicto.

La segunda parte se compila en "Ajustes a la Cooperación Colombiana en el siglo xxı", donde se propone la instrumentalización de la cooperación internacional para el desarrollo a través de la política exterior desde una mirada interdisciplinaria que pone el énfasis en cómo la cooperación internacional es definitivamente $y$, sin lugar a dudas, un instrumento de política exterior que debería tener dos extremos en su Estrategia País de Cooperación Internacional: la mejora de la calidad de vida de las comunidades a través del incremento de la competitividad de la vocación productiva de los territorios y la articulación de estos excedentes generados por este incremento, para aprovechar las herramientas de la política comercial como tratados de libre comercio, acuerdos comerciales, acuerdos de promoción y protección a la inversión extranjera, etc.

Un segundo capítulo de esta segunda parte se traduce en el análisis de Colombia en los asuntos internacionales: la interrelación entre identidad, estatus y cooperación Sur-Sur que permite entender el rol que desempeña Colombia como oferente en el cambio propio de la dinámica de la cooperación, que ha convertido al país en un interesante socio en temas de intercambio de buenas prácticas en temas de seguridad y agrícolas y que permite recrear escenarios de cooperación entre iguales incluso entre territorios y regiones al interior del país, y con el apoyo y participación de organismos internacionales descentralizados y de actores no convencionales como organismos no gubernamentales, centros de investigación, etc.

Esta segunda parte, la cierra un muy interesante capítulo sobre la participación de las organizaciones de la sociedad civil en los procesos de cooperación Sur-Sur, como catalizadores y líderes en temas relacionados con gobernanza y gestión de recursos técnicos y financieros para la construcción de territorios que, con buenas prácticas de gobierno y una buena estrategia de marketing territorial, pueden acceder no solo a recursos e intercambio de tecnologías y técnicas, sino a protagonizar liderazgos regionales que consoliden proyectos participativos de desarrollo sostenible.

La tercera parte pone de manifiesto la importancia de conocer, finalmente, cuánto de cooperación hay en la cooperación internacional, retomando ejemplos de cooperación del Sur para el Sur en el siglo xIx y cerrando 
con el capítulo de la Crisis global y el conflicto nacional a la cooperación con el mundo, como la parte reflexiva del aportante libro que enfatiza sobre la necesidad de derrumbar los mitos existentes en la cooperación internacional para darle su verdadero valor $y$ aprovechar mejor sus beneficios, compensando los costos que esta implica y realizando una relectura que facilite su optimización y vuelva a convertirse en la protagonista del desarrollo, dado que ya no se requiere reconstruir unos países devastados por la guerra, como cuando surgió la cooperación internacional en 1945, sino que se hace urgente convertirla en respuesta para cumplir con los objetivos de desarrollo sostenible oDs y poder construir sinergias entre las comunidades y contextos equilibrados para las comunidades.

El libro indudablemente constituye un espacio de diálogo y relectura a la cooperación internacional, para entenderla como algo real, para conocerla y caracterizarla desde visiones más amplias e interdisciplinarias que convoquen a investigar desde la academia como espacio de interacción con los territorios y las comunidades, para dar respuesta y tender puentes hacia el infinito en un posconflicto en el que todo parece nuevo, pero que lo que necesita de la academia, la sociedad civil y los demás actores es revisitarla para que amplíe su capacidad de interacción y desde su esencia consolide espacios para la construcción colectiva de diálogos sociales, culturales que jalonen inevitablemente lo político, económico e internacional.

La agenda pendiente en cooperación internacional para el mundo y para Colom- bia después de leer este libro es inspiradora y muy amplia como punto de partida en temas que dentro de la cooperación internacional no solo no se han estudiado, sino que se han ignorado, desconociendo los virajes que pudieran representar para el propio devenir de las comunidades como mecanismo de apropiación de los territorios, tales como perfiles y metodologías para acceder a los recursos de cooperación de manera más expedita, pero también instrumentos de construcción de una política pública de cooperación que no excluya ningún actor y en el que la academia sea protagonista, con investigadores expertos con redes de conocimiento y buenas prácticas en los territorios.

Una cartografía de la cooperación internacional más allá de la ubicación de proyectos, de problemáticas comunes sujetas de cooperación, también puede constituirse en un interesante producto derivado de una investigación juiciosa y exhaustiva, pero que no puede ni pretende abarcarlo todo.

La invitación clara que queda a partir de la lectura del libro Cooperación y academia: Una relación pendiente en Colombia, es a convocar a la cooperación como eje de investigación, como articulador pedagógico de formación y como una posibilidad sine qua non de crecimiento y desarrollo sostenible para la mayoría de los territorios afectados por el conflicto en Colombia, donde todos los actores sean protagonistas y puedan participar en la construcción de sus propios territorios desde las distintas dimensiones de análisis y perspectivas existentes. 